\title{
Performance and working mechanism of tension-compression composite anchorage system for earthen heritage sites
}

\author{
Donghua Wang ${ }^{1}$, Kai Cui ${ }^{1,2^{*}} \mathbb{D}$, Guopeng $W^{1}{ }^{1,2}$, Fei Feng ${ }^{1}$ and Xiangpeng Yu ${ }^{1}$
}

\begin{abstract}
Although the fully grouted tension anchorage system (T-anchorage system) has been widely used in the field of anchoring of earthen heritage sites, it has always suffered from the failure of the bolt-slurry interface debonding and the strong attenuation of the shear stress of the bolt-slurry interface along the embedment length. In this article, a new type of fully grouted tension-compression composite anchorage system (TC-anchorage system) is proposed, which is made up of a pressure bearing system with the same diameter of the anchor hole at the end of the tension bolt. The in situ anchorage, pull-out test and interfacial stress-strain monitoring were carried out for the T-anchorage systems and the TC-anchorage systems. This was based on the preliminary analysis and comparison of the structure and working mechanism of the two anchorage systems. The test results show that: the average ultimate load of the TC-anchorage system is about 40\% higher than that of the T-anchorage system. TC-anchorage systems have the characteristics of small elastic deformation and large plastic deformation. The strain at the bolt-slurry interface varies progressively along the embedded length with the increase of load in a positive skewness-bimodal-negative skewness curve. The working mechanism of TC-anchorage systems includes three progressive stages: bolt-slurry interface debonding, conical slurry formation and slurry extrusion. The research conclusion provides a reference for the application of TC-anchorage systems in the protection and reinforcement of earthen heritage sites.
\end{abstract}

Keywords: Earthen heritage sites, Fully grouted tension-compression composite anchorage system (TC-anchorage system), Fully grouted tension anchorage system (T-anchorage system), Anchorage performance, Working mechanism

\section{Introduction}

Earthen heritage sites are the cultural heritage with soil as the main building material. They are the direct physical evidence of the origin and evolution of human civilization and the important historical roots of excellent traditional culture. They have great historical, artistic, and scientific value. Earthen heritage sites are abundant in the mainly arid zones of Africa, Asia, North and South America, and the Middle East and are also quite rich in types [1]. For example, in China's arid environment and

\footnotetext{
*Correspondence: cuik09@lut.edu.cn

${ }^{1}$ Western Center for Disaster Mitigation in Civil Engineering of Ministry of Education of China, School of Civil Engineering, Lanzhou University of Technology, Langongping Road No. 287, Lanzhou 730050, People's Republic of China

Full list of author information is available at the end of the article
}

along the Silk Road, the Great Wall [2] and its subsidiary buildings from the Qin Dynasty to the Ming Dynasty, as well as Buddhist temple sites and ancient cities in different historical periods are representatives of earthen heritage sites [1]. However, earthen heritage sites have been eroded by various natural forces such as wind erosion, rain erosion, freezing and thawing, earthquakes and human activities for a long time. Collapse, fissure and excavation, which directly or indirectly lead to the destabilization and destruction of earthen heritage sites, have been widely developed and have become the primary problem endangering the safe preservation of earthen heritage sites [3]. Therefore, the protection methods of stability control of earthen heritage sites have become a research hotspot. 
Since the 1960s, fully grouted tension bolts (T-bolts) have been used in civil and mining engineering as temporary and permanent reinforcement components, and have made considerable progress in practical experience and theoretical research [4-6]. T-anchorage system is fully taken into account the characteristics of making maximum use of the existing structure, repairing the structure in a hidden way, and adjusting the strength of the repairs to the appropriate degree. As an attempt, $\mathrm{T}$-anchorage system has been applied to the reinforcement of earthen heritage sites along the Silk Road since the 1990s [7]. However, anchorage materials widely used in conventional civil engineering reinforcement fields, such as metal bolts [8], cement mortar [9], and resin slurry [10], are poorly compatible with earthen heritage sites in physical, mechanical, and chemical properties. Consequently, the above-mentioned bolts and slurry have insufficient durability, and the deformation of them are respectively inconsistent with that of earthen heritage sites [1]. Therefore, these anchorage materials can not be directly applied to the reinforcement of earthen heritage sites, and the corresponding research results can only be used as a reference.

However, it should be noted that based on the conservation philosophy of "minimal intervention, maximum compatibility and unchanged status", the current research focuses on the selection of anchorage materials, optimization of anchorage technology, and macroanchorage performance and mechanism of $\mathrm{T}$-anchorage system. Researches on the types of bolts have successively emerged such as wood bolts [11], bamboo bolts [12], bamboo rebar composite bolts [13], geotechnical filaments [14], and GFRP bolt [15]. On grouting materials, modified grout based on high modulus potassium silicate solution [16], glutinous rice paste [17], modified polyvinyl alcohol [18] as the main cementing materials and modified grout based on calcined ginger nuts [19] as the main material have appeared successively. However, in T-anchorage system of earthen heritage sites, the physical and mechanical properties of bolt and slurry cannot be perfectly compatible with that of earthen heritage sites, which leads to the main failure of bolt-slurry interface debonding and the shear stress of bolt-slurry interface attenuates strongly along the embedment length. Therefore, it is difficult to improve the performance of anchorage system only by improving the physical and mechanical indexes of slurry and bolt materials. Moreover, with the continuous development of anchorage technology, "short embedment length, high anchorage force, large deformation resistance" excellent anchorage performance has become an inevitable trend of the development of earthen heritage sites anchorage system. Therefore, from the point of view of interaction mechanism between bolt and slurry, synergistic use of compression and shear resistance of slurry can improve the anchorage performance of anchorage system of earthen heritage sites more comprehensively.

In view of the above situation and few reports of tension-compression composite anchorage in the field of earthen heritage sites anchorage, a new type of fully grouted tension-compression composite anchorage system (TC-anchorage system) is proposed in this article, which is made up of a pressure-bearing body with the same diameter of the anchor hole at the end of the tension bolt. It is hoped that the TC-anchorage system can improve the anchorage force per unit embedment length and the large deformation resistance of the structure, thereby reducing the protective damage caused by the existing $\mathrm{T}$-anchorage system, increasing the safe storage of anchorage system against large deformation and providing a more reasonable spatio-temporal continuity of the stress process at the bolt-slurry interface. Therefore, TC-anchorage system and T-anchorage system were selected as the research objects, and the structures and working mechanisms of the two anchorage systems were preliminarily expounded. In-situ anchorage, pull-out test, and stress-strain monitoring of bolt-slurry interface were carried out for TC-anchorage system and T-anchorage system. Then, on the test results, the performance of the TC-anchorage system is analyzed based. According to the interaction between bolt and slurry, the working mechanism of the TC-anchorage system is discussed. The applicability of TC-anchorage system in the reinforcement of the mechanical stability of earthen heritage sites is evaluated. This study offers a reference and basis for further theoretical research and engineering application of TC-anchorage system for earthen heritage sites.

\section{Structure and working mechanism of TC-anchorage system}

Researches on the performance and working mechanism of T-anchorage system have been carried out $[11,16,17]$ : (1) The excavation of the damaged T-anchorage system can be observed: sites soil and slurry remained intact; slurry-soil interface remained tight; debonding and decoupling occurred at the bolt-slurry interface (Fig. 1). In $\mathrm{T}$-anchorage system, there is a sequential transmission mode of bolt-slurry-soil under pull-out load, and the difference of elastic modulus between slurry and bolt is much larger than that between slurry and soil, which leads to the following situations: displacement of the anchor bolt head quickly passes to the end of the bolt; relative movement occurs between bar and slurry in tension anchorage section; bolt produces stronger axial shear and weaker radial extrusion on the thin-bedded slurry around it [17]. The debonding and decoupling failure modes of 
bolt-slurry interface include two forms (Fig. 2): Slurry shearing-bolt shears the thin-bedded slurry around it; Dilational slip-when bolt is forced to move forward under pull-out load, if the confining pressure of slurry stored on bolt is not enough or uneven, bolt ribs will not cut slurry ribs but climb slurry ribs. The bolt ribs will simultaneously extrude surrounding slurry ribs radially or expand and extrude slurry to the side of weak confining pressure, and bolt will appear undulating slip relative to the slurry. (2) The stress at the bolt-slurry interface is transmitted directly from the front end of embedment length to the back end. It distributes unevenly in the embedment length and attenuates sharply toward the back end of the embedment length. This results in

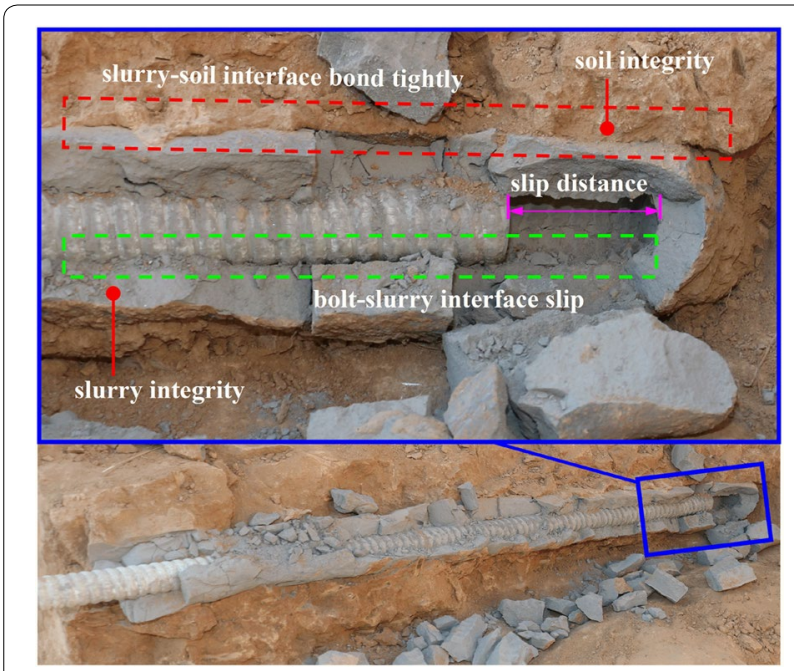

Fig. 1 Physical excavation after pull-out failure of T-anchorage system obvious stress concentration at the bolt-slurry interface at the front end of embedment length $[17,18]$ and the bond stress easily exceeds the ultimate bond strength of the interface, resulting in interface softening, which leads to the debonding and decoupling of the bolt-slurry interface [20]. Therefore, although the compressive strength of the slurry is much greater than its shear strength, the pull-out performance of T-anchorage system depends mainly on the shear strength of the thin-bedded slurry around the bolt, which fails to make full use of the compressive properties of slurry.

The fully grouted tension-compression composite bolt (TC-bolt) used in this study is different from T-bolt conventional used in earthen sites. Its structure is similar to the " $\mathrm{T}$ " type, in other words, a pressure-bearing body is consolidated at the end of T-bolt. Pressure-bearing body includes hollow wedge lock and hollow truncated cone. The inner surface of the hollow truncated cone is mosaic with the outer surface of the hollow wedge lock. The hollow wedge lock is fixed at the end of the bolt and the hollow truncated cone is fixed with the hollow wedge lock, which forms a TC-bolt. The maximum axial section of hollow truncated cone is equal to that of cylindrical anchor hole. Tension section is from the orifice part to the front end of the pressure-bearing body and pressurebearing section is from the front end of the pressurebearing body to the end of the bolt. The structure and stress diagram of TC-bolt are shown in Fig. 3.

The working mechanism of TC-anchorage system is more reasonable than that of $\mathrm{T}$-anchorage system. When the anchor head is under low load, the tension transfers from the front end of the embedment length to the back end and relative displacement trend or relative displacement occurs between bolt and slurry. The bolt in front of

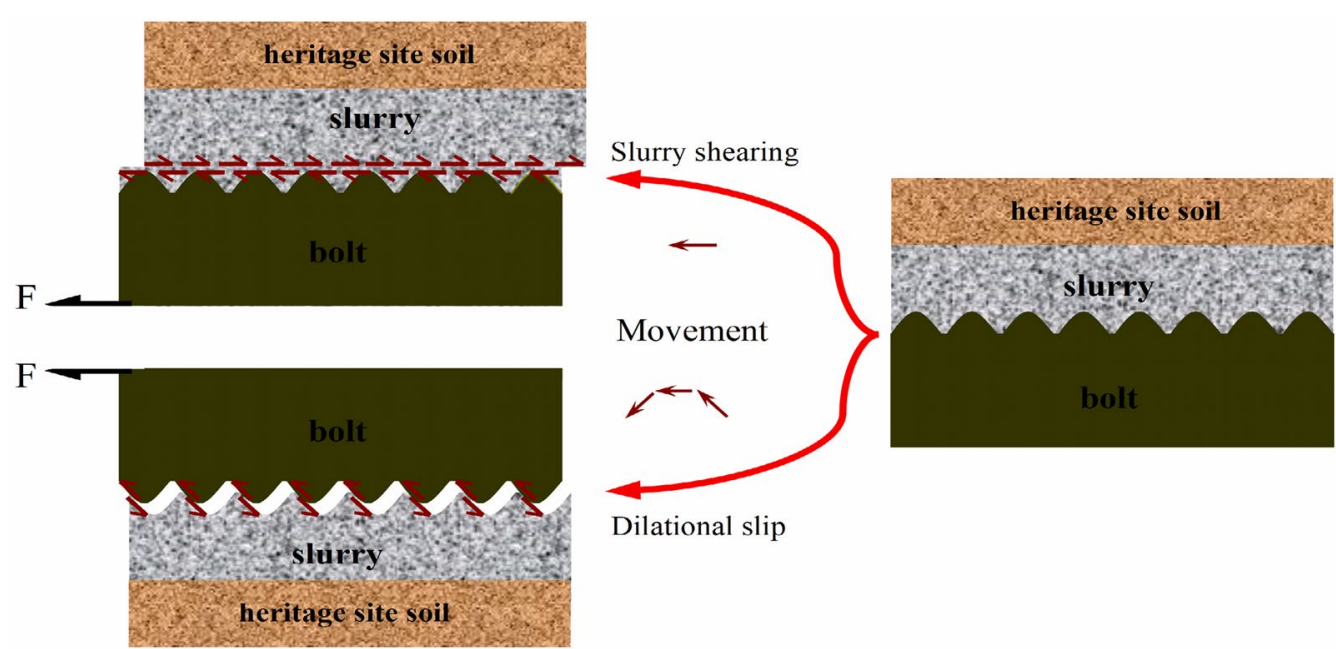

Fig. 2 Two types of debonding and decoupling of bolt-slurry interface in T-anchorage system 


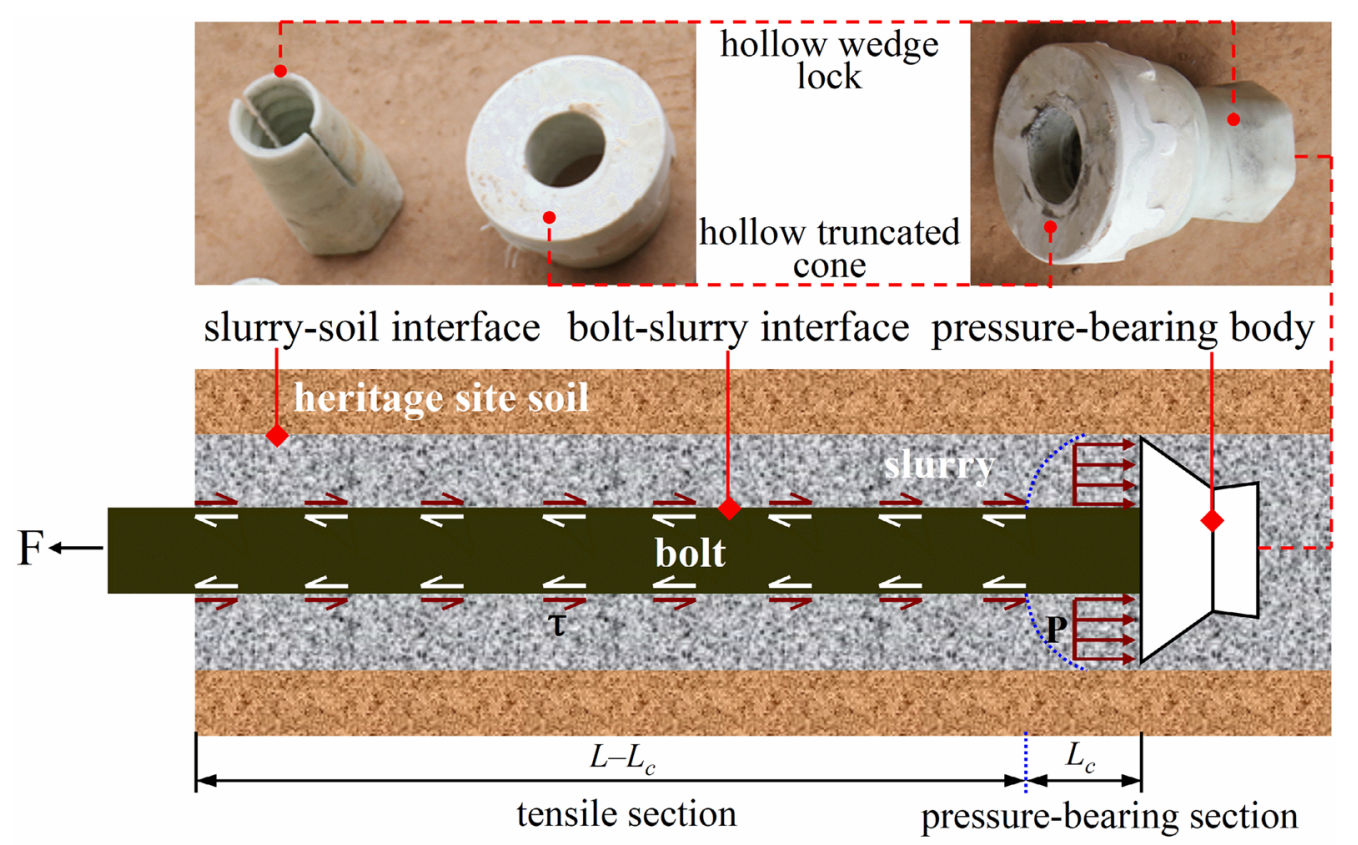

Fig. 3 TC-bolt structure and interaction force between bolt and slurry. F: drawing force; t: shear stress; P: pressure; L: embedment length; L: length of pressure-bearing section; blue dot lines: boundary between tension section and pressure-bearing section

the hollow truncated cone is in tension state, forming a tension anchorage section. The bolt-slurry interface of the tension section at the front end of embedment length bears the main pull-out effect and the main displacement also occurs here. With the increasing load, the debonding and decoupling of the bolt-slurry interface transfer to the back end of embedment length and the displacement of the $\mathrm{TC}$-anchorage system larger and larger. When the load is transferred to the hollow truncated cone at the end of bolt, that is, the bolt pulls the hollow truncated cone forward to produce a relative displacement trend or displacement. In this process, the hollow truncated cone extrudes the slurry located in the front of it, which makes it in a pressure state and forms a pressure-bearing anchor. With the aggravation of drawing effect, the extrusion effect of pressure-bearing body on slurry becomes stronger and stronger. If the stiffness of the bolt structure is enough, the slurry in front of the hollow truncated cone will continue to yield and the main effective pull-out section will gradually move back. Therefore, the bearing body formed by the tensile section and the pressure-bearing section bears the load on the anchor head. TC-bolt's acceptance mode greatly reduces the load on the compressive anchorage section and the tension anchorage section respectively, and effectively reduces the stress concentration at the bolt-slurry interface. Therefore, the ultimate uplift bearing capacity of the TCanchorage system is higher than that of the T-anchorage system, which can effectively save the embedment length.
Considering that the embedded length of the interface determines the main pull-out effect of the anchorage system, the stress process of the bolt-slurry interface of the $\mathrm{TC}$-anchorage system has excellent space-time continuity and the stress concentration of the bolt-slurry interface is small, which enables the synergistic utilization of compressive and shear properties of slurry to be fully achieved.

According to the mechanical model of TC-anchorage system mentioned above (Fig. 3) and the equations of calculating T-anchorage system in the code [21, 22], it is considered that the ultimate anchorage force of $\mathrm{TC}$-anchorage system consists of tension section anchorage force and pressure-bearing section anchorage force. The equations for calculating the ultimate anchorage force of TC-anchorage system are as follows:

$$
\begin{aligned}
& P_{T C}=P_{t}+P_{c} \\
& P_{t}=\mu \pi d\left(L-L_{c}\right) \tau_{f} \\
& P_{c}=\frac{\pi\left(D^{2}-d^{2}\right)}{4} f_{c u}
\end{aligned}
$$

where $P_{T C}$ is the ultimate anchorage force of TC-anchorage system $(\mathrm{kN}) ; P_{t}$ is the anchorage force of tension section $(\mathrm{kN}) ; P_{c}$ is the anchorage force $(\mathrm{kN})$ of pressurebearing section $(\mathrm{kN}) ; \mu$ is the influence factor of embedment length on bond strength; $d$ is the diameter of bolt $(\mathrm{mm}) ; L$ is the embedment length $(\mathrm{mm}) ; \tau_{f}$ is the standard 
bond value between bolt and slurry in the tension section $(\mathrm{kPa}) ; D$ is the diameter of anchor hole $(\mathrm{mm}) ; L_{\mathrm{c}}$ is the length of pressure-bearing section $(\mathrm{mm}) ; f_{c u}$ is the uniaxial unconfined compressive strength of slurry $(\mathrm{kPa}) ; \mu, \tau_{f}$, $L_{\mathrm{c}}$ and $f_{c u}$ can be obtained from the corresponding tests.

For the calculation Eq. (3) of anchorage force in pressure section, there are three aspects which do not match reality very well and need to be improved: (1) $f_{c u}$ is the unconfined compressive strength of slurry, while slurry is in the state of three-dimensional stress, and the value calculated by $f_{c u}$ is smaller than the actual compressive strength value; (2) only the crushing of slurry in pressure section is considered, but the pull-out effect formed by the cohesion between slurry and soil is not considered; (3) although the force between bolt and slurry in the pressure-bearing section is less than that in the tension section, there is also a certain pull-out resistance. Considering that the shear stress of bolt-slurry interface decreases along embedment length and the pressurebearing section is at the end of embedment length, the pull-out force formed at the bolt-slurry interface in the pressure-bearing section is neglected. Therefore, the ultimate anchorage force of $\mathrm{TC}$-anchorage system calculated by Eq. (1) needs to be improved more accurately.

\section{Methods \\ Research objective}

(1) To explore the failure modes, ultimate loads, loaddisplacement curve characteristics, and the timespace law of stress transfer at the bolt-slurry interface of TC-anchorage system.

(2) Based on the analysis of the performance and interface stress mechanism of the TC-anchorage system, the working mechanism of TC-anchorage system is preliminarily explored.

(3) Comparing and analyzing the anchorage performance and working mechanism of $\mathrm{TC}$-anchorage system and $\mathrm{T}$-anchorage system, and evaluating the applicability of TC-anchorage system in earthen heritage sites anchorage.

\section{Conceptual design}

First, bolts and the samples of grout and earthen heritage sites were made in the laboratory. Next, their physical and mechanical indexes were tested. Final, in situ pullout tests were carried out for the TC-anchorage system and T-anchorage system. Two parallel samples of bolts were set for each anchorage system and strain gauges were used to monitor the stress-strain of the bolt-slurry interface.

\section{Bolt preparation}

The glass-fibre-reinforced plastic (GFRP) bolt is selected as the test bolt. The hollow truncated cone and hollow wedge lock are both GFRP materials. The inner spiral surface and outer surface of hollow wedge lock were coated with appropriate epoxy resin. Then, the hollow wedge lock was locked at the end of the bolt, and finally the hollow truncated cone was installed with hollow wedge lock. After the structure of the pressure-bearing body was consolidated, strain gauges were laid at a distance of $20 \mathrm{~cm}$ on the surface of the bolt. The strain gauge model is BE120-3BB(11)-X30 (resistance: $120.0 \pm 0.3 \Omega$, sensitivity: $2.17 \pm 1 \%$ ) produced by AVIC. The physical objects and the locations of strain gauges of TC-bolt and T-bolt are shown in Fig. 4.

\section{Sample preparation}

The main materials used in this testing include water, $\mathrm{SH}$ solution, quicklime, fly ash, and heritage site soil. The water is tap water, whose quality meets the specifications of the "Concrete Water Standards (JGJ63-2006)" [23]. SH is a new type of polymer material and a liquid modified polyvinyl alcohol with a density of $1.09 \mathrm{~g} \mathrm{~cm}^{-3}$ and it has the advantages of non-toxicity, environmental protection, and excellent physical, chemical, and mechanical properties. The mass concentration of the original $\mathrm{SH}$ solution is 5\% [24]. The mass concentration of the $\mathrm{SH}$ solution used in the test is $1.5 \%$, which is created by adding laboratory water to the original solution. Quicklime belongs to industrial grade $\mathrm{I}$, in which $\mathrm{CaO}$ content is 93.6\%. The fly ash is also industrial grade I and has a particle size of $0.005-0.1 \mathrm{~mm}$. Its chemical composition is shown in Table 1. The heritage site soil is retrieved from the in situ test site and its particle size is less than $0.1 \mathrm{~mm}$ after mechanical grinding. The main physical parameters of heritage site soil are obtained after it is tested according to the "Standard for Soil Test Method (GB/T501231999)" [25], as shown in Table 2.

$\mathrm{SH}-(\mathrm{CaO}+\mathrm{C}+\mathrm{F})$ slurry was used as grouting material. It was composed of quicklime $(\mathrm{CaO})$, ground site soil (C) and fly ash (F) mixed with modified polyvinyl alcohol $(\mathrm{SH})$ solution. The mass mixing ratio of $\mathrm{SH}$ $(\mathrm{CaO}+\mathrm{C}+\mathrm{F})$ slurry was $\mathrm{M}_{\mathrm{CaO}}: \mathrm{M}_{\mathrm{C}}: \mathrm{M}_{\mathrm{F}}=3: 2: 5$ and $\mathrm{M}_{\mathrm{SH}}$ : $\mathrm{M}_{\mathrm{CaO}+\mathrm{C}+\mathrm{F}}=1: 1$. Slurry sample preparation was carried out in accordance with the "Technical Regulations for Soil Heritage Protection Test (WW/T0039-2012)" [26]. The slurry was shaped into a cubic sample with a size $70.7 \mathrm{~mm} \times 70.7 \mathrm{~mm} \times 70.7 \mathrm{~mm}$. The ambient temperature and relative humidity of the laboratory were approximately $20{ }^{\circ} \mathrm{C}$ and $25 \%$, respectively. The samples were numbered and demolded after being molded for $24 \mathrm{~h}$, and then, they were cured in the laboratory for 30 days. 


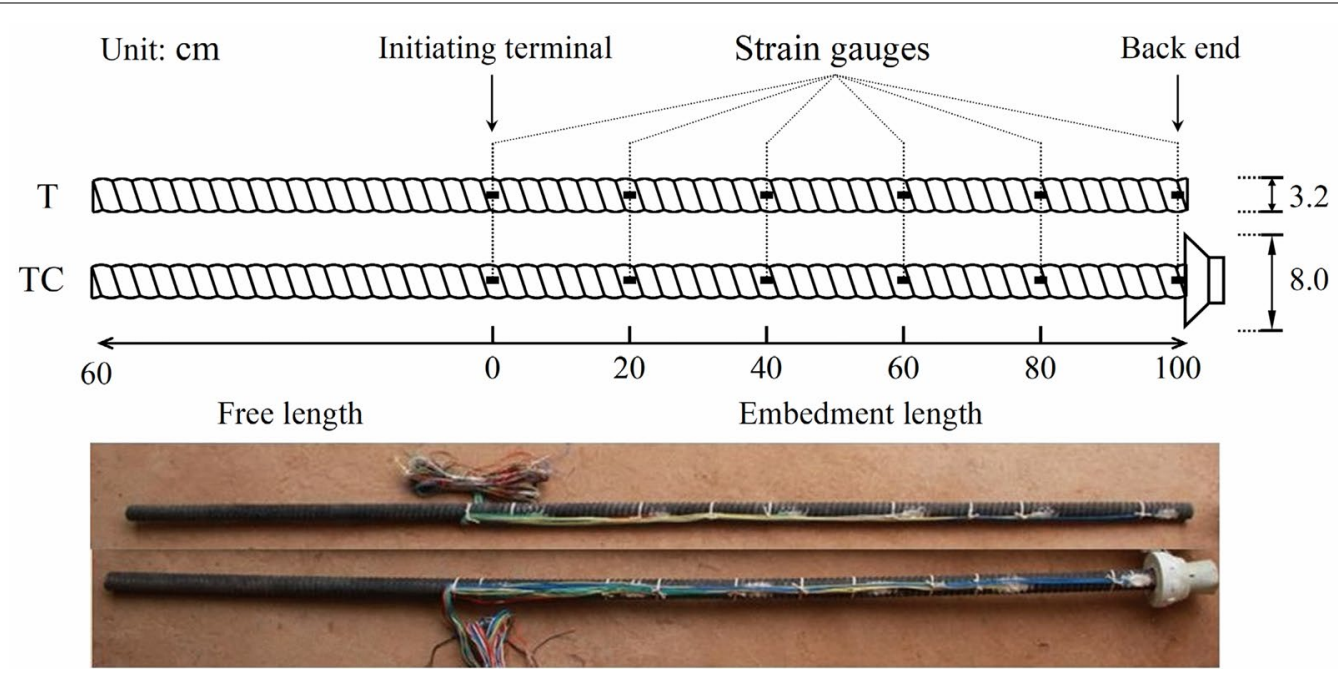

Fig. 4 The physical objects and the locations of strain gauges of TC-bolt and T-bolt

Table 1 Chemical composition and content of fly ash

\begin{tabular}{llllllll}
\hline Constitution & $\mathrm{SiO}_{\mathbf{2}}$ & $\mathbf{A l}_{\mathbf{2}} \mathbf{O}_{\mathbf{3}}$ & $\mathrm{Fe}_{\mathbf{2}} \mathrm{O}_{\mathbf{3}}$ & $\mathrm{CaO}$ & $\mathbf{M g O}$ & $\mathbf{K}_{\mathbf{2}} \mathbf{O}+\mathbf{N a}_{\mathbf{2}} \mathbf{O}$ & lgnition loss \\
\hline Mass fraction (\%) & 54.11 & 34.44 & 5.34 & 0.69 & 0.70 & 1.23 & 1.08 \\
\hline
\end{tabular}

Table 2 Properties of heritage site soil

\begin{tabular}{|c|c|c|c|c|c|c|c|c|}
\hline Test sample & $\begin{array}{l}\text { Natural } \\
\text { moisture } \\
\text { content (\%) }\end{array}$ & $\begin{array}{l}\text { Dry density } \\
\left(\mathrm{g} \mathrm{cm}^{-3}\right)\end{array}$ & Liquid limit (\%) & Plastic limit (\%) & $\begin{array}{l}\text { Powder } \\
\text { content (\%) }\end{array}$ & $\begin{array}{l}\text { Clay content } \\
\text { (\%) }\end{array}$ & Gradation & Category \\
\hline Site soil & 0.56 & 1.56 & 30.75 & 18.15 & 56.33 & 15.12 & Poor & Silty clay \\
\hline
\end{tabular}

Table 3 Physical and mechanical indexes of anchorage materials field

\begin{tabular}{|c|c|c|c|c|c|c|c|c|c|}
\hline Material types & Composition & $\begin{array}{l}\text { Natural } \\
\text { density } \\
\left(\mathrm{g} \mathrm{cm}^{-3}\right)\end{array}$ & $\begin{array}{l}\text { Moisture } \\
\text { content } \\
(\%)\end{array}$ & Porosity (\%) & $\mathrm{C}(\mathrm{kPa})$ & $\Phi\left({ }^{\circ}\right)$ & $\begin{array}{l}\text { Compressive } \\
\text { strength } \\
\text { (MPa) }\end{array}$ & $\begin{array}{l}\text { Tensile } \\
\text { strength } \\
\text { (kPa) }\end{array}$ & $\begin{array}{l}\text { Elastic } \\
\text { modulus } \\
\text { (MPa) }\end{array}$ \\
\hline Rammed earth & Silt clay & 1.58 & 2.15 & 42.32 & 145.1 & 48.3 & 0.43 & 90 & $0.99 \times 10^{2}$ \\
\hline $\mathrm{SH}-(\mathrm{CaO}+\mathrm{C}+\mathrm{F})$ & $\mathrm{SH}, \mathrm{CaO}$, Silt clay, Fly ash & 1.15 & 3.05 & 42 & 95.61 & 41.92 & 1.92 & 170 & $1.88 \times 10^{2}$ \\
\hline GFRP bolt & Glass fiber reinforced plastic & 1.55 & - & - & - & - & 117 & $1.18 \times 10^{6}$ & $5.55 \times 10^{4}$ \\
\hline
\end{tabular}

\section{Test for physical and mechanical indicators of materials}

The undisturbed heritage site soil sample was shaped into a cubic test block of the same size as the mortar according to the abovementioned specifications "(WW/ T0039-2012)" [26]. Parameters such as the density, porosity, moisture content, strength, and elastic modulus of the soil samples in the mortar and the original site were determined in accordance with the "Standard for Soil Test Method (GB/T50123-1999)" [25]. The physical and mechanical indexes of GFRP bolts were determined by consulting the quality inspection report provided by the producer. The test results of physical and mechanical indexes of anchorage materials are shown in Table 3.

\section{In situ anchorage and pull-out test}

An abandoned rammed earth wall near the Great Wall of Ming Dynasty in Linze Section of Zhangye City, Gansu Province, China, was selected as the anchorage test site. The wall was rammed with red sand on natural basis. The thickness of rammed layer is $18-22 \mathrm{~cm}$. The wall profile 
is trapezoidal with $5 \mathrm{~m}$ bottom width, $3 \mathrm{~m}$ top width, and $3.5 \mathrm{~m}$ residual height. The anchorage systems were maintained for more than 30 days after completion of the steps of hole formation, anchor insertion in the middle, high pressure grouting and secondary grouting, and then pull-out tests were carried out. In situ test anchorage parameters are shown in Table 4.

The anchorage drawing instrument was the Beijing HiChance HCYL-60 comprehensive anchorage parameter measurement instrument. The hole diameter at the centre of the lifting jack was $60 \mathrm{~mm}$, and the working stroke of the cylinder was $120 \mathrm{~mm}$, with a measurement range of $0-500 \mathrm{kN}$. Field pull-out test system and equipments are shown in Fig. 5. The pull-out tests followed the "Code for the design and protection of dry earth sites for protection and reinforcement (WW/T 00382012)" [21] and the "Technical specification for rock and soil anchorage bolts and shotcrete support engineering (GB 50086-2015)" [27] and referred to the cyclic loading method of previous drawing tests $[17,18]$. Each stage is increased or decreased by $4 \mathrm{kN}$ as the preset drawing load. The maximum value of the load in the latter cycle is $4 \mathrm{kN}$ larger than the maximum value of the current cycle, that is, the pulling load is carried out according to the " $0 \rightarrow 4 \rightarrow 8 \rightarrow 4 \rightarrow 8 \rightarrow 16 \rightarrow 8 \rightarrow 4 \rightarrow \ldots(\mathrm{kN})$ " method. Stop loading when the load is applied to the preset load. When the difference of displacement meter display number for three consecutive times is not more than $0.01 \mathrm{~mm}$, it is considered that the anchorage system has reached a stable state, and the next stage load can be implemented. Ultimately, all bolts are stopped because the displacement of anchor head can not convergent and the load can not be increased any more.

\section{Results and analysis}

\section{Ultimate load}

As shown in Fig. 6, the average ultimate pull-out loads of the TC-anchorage system and T-anchorage system are $26.30 \mathrm{kN} / \mathrm{m}$ and $18.85 \mathrm{kN} / \mathrm{m}$, respectively. Ignoring the difference of bolts structure and assuming that the shear stress distributes uniformly along the embedment length, the average shear strength of the bolt-slurry interface of $\mathrm{TC}$-anchorage system and $\mathrm{T}$-anchorage system are $0.26 \mathrm{MPa}$ and $0.19 \mathrm{MPa}$, respectively. Obviously, the average interfacial shear stress of TCanchorage system increases by about $40 \%$ compared with that of T-anchorage system. This benefits from the positive role played by TC-bolt structure in improving

Table 4 Arrangement of parameters of test groups in field test

\begin{tabular}{lllllll}
\hline Group & Anchor type & Bolt diameter $(\mathbf{m m})$ & $\begin{array}{l}\text { Pressure-bearing } \\
\text { body diameter } \\
(\mathbf{m m})\end{array}$ & Borehole diameter $(\mathbf{m m})$ & $\begin{array}{l}\text { Embedment length } \\
(\mathbf{c m})\end{array}$ & Anchorage angle $\left(^{\circ}\right)$ \\
\hline TC1 & TC-bolt & 32 & 80 & 80 & 100 & 10 \\
TC2 & & & - & & \\
T1 & T-bolt & & & & \\
T2 & & & & & & \\
\hline
\end{tabular}

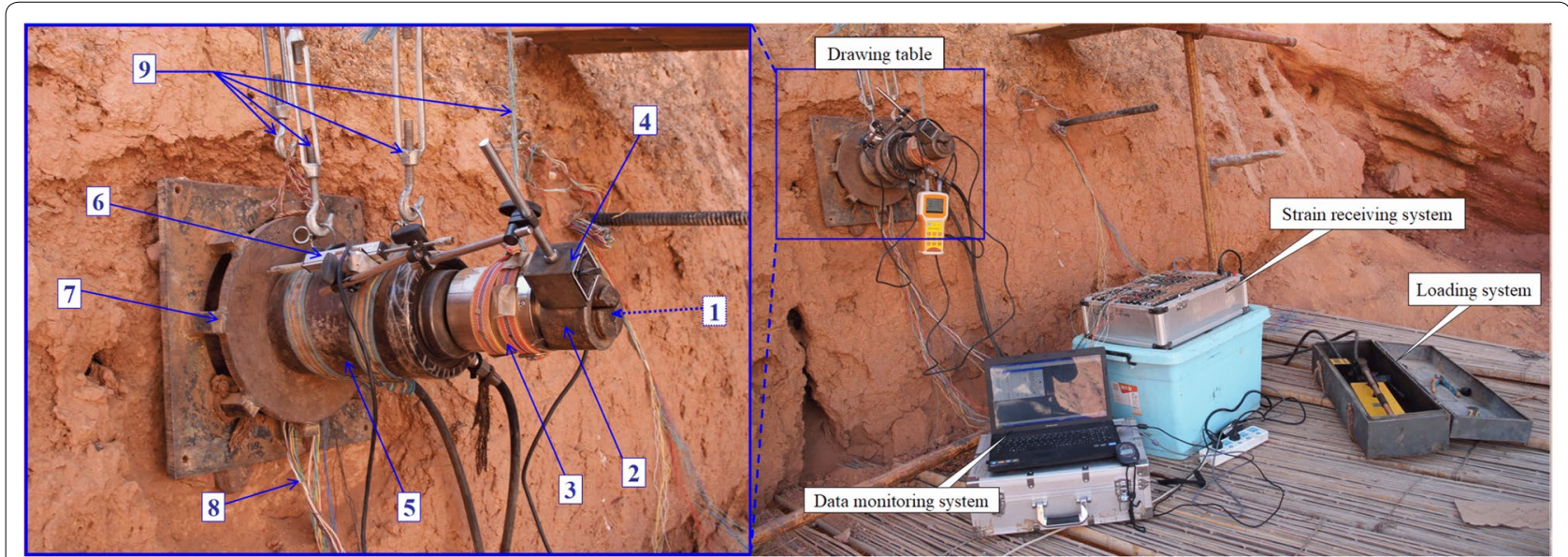

Fig. 5 Field drawing test system and equipments. 1: bolt; 2: anchor head; 3: pressure sensor; 4: fixed bracket; 5: lifting jack; 6: displacement sensor; 7: backing plate; 8: leads; 9: catenary ropes 


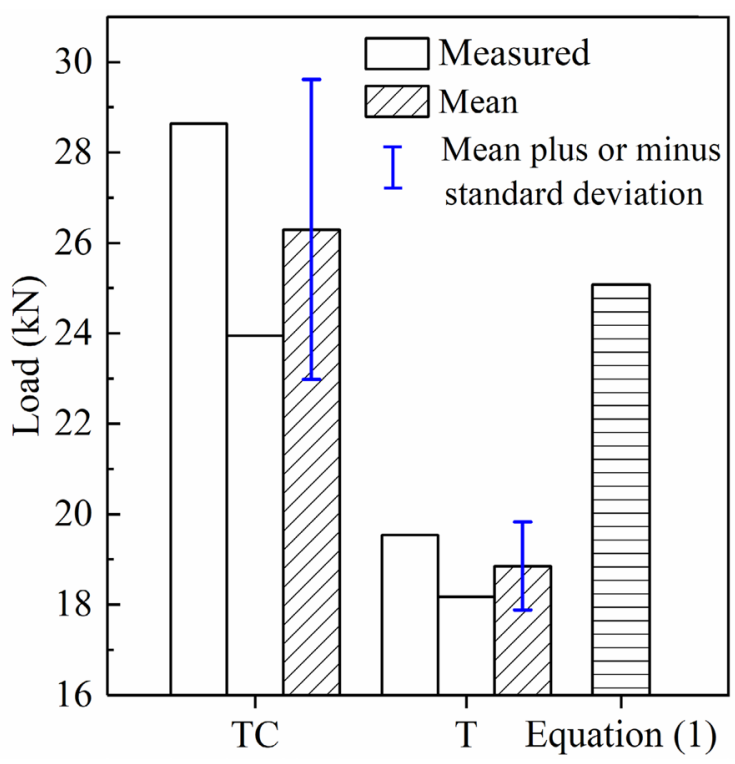

Fig. 6 Measured ultimate load and means of measured ultimate loads of two types of anchorage systems and the calculated value of ultimate load

anchorage capacity, which is also supported by the research of different research fields, different materials anchors and different bolt structures, as well as similar research on changing the stress mode between bolt and slurry by changing bolt diameter [28-30]. When comparing with the practical design value $(3 \mathrm{kN} / \mathrm{m})$ [31] from the perspective of stabilisation, the anchorage capacity provided by TC-anchorage system can better meet the protection requirements of earthen heritage sites.

According to the results of laboratory tests and field tests, the following parameters can be obtained: $\tau_{f}$ is equal to the average shear strength of bolt-slurry interface of T-anchorage system, i.e., $\tau_{f}=0.19 \mathrm{MPa}, \mu=1$, $L_{\mathrm{c}}=100 \mathrm{~mm}$ and $f_{c u}=1.92 \mathrm{MPa}$. The value of $P_{T C}$ calculated from Eq. (1) is $25.07 \mathrm{kN}$. From Fig. 6, it can be seen that $P_{T C}$ is less than the actual ultimate load mean of TC-anchorage system. This may be mainly due to the uniaxial unconfined compressive strength of $f_{c u}$ used in calculating $P_{c}$, while the slurry in pressure-bearing section is in a three-dimensional stress state during the actual stress process, so $f_{c u}$ is less than the actual compressive strength of slurry, resulting in a slightly smaller calculation result $P_{T C}$ than the mean test value. For practical engineering, the calculation of ultimate load of the TC-anchoring system using $f_{c u}$ is biased towards safety.

\section{Load-displacement}

As shown in Fig. 7, there are three inflection points and four stages in load-displacement curve of TC-anchorage system during cyclic loading process. The load-displacement curve is in the elastic stage before the first inflection points (yield point), which is basically linear. The curve between yield point and the second inflection point (reinforcement point) is in the plastic stage, which shows a non-linear and non-uniform increasing relationship. In this stage, the bolt-slurry interface enters the stage of full plasticity, and the pressure-bearing body and slurry are compressed tightly into rigid body, which can be proved from each cyclic path of the load-displacement curve. No response is observed for displacement of each cyclic path regardless of load rise or fall. Only when the load exceeds the maximum cyclic load of the previous stage and increases into the next stage of larger cyclic load, the displacement can continue to increase. The curve between the reinforcement point and the third inflection point (peak point) is reinforcement service stage, and the load-displacement curve shows an obvious nonlinear non-uniform increase relationship. When the load reaches peak point, load-displacement curve enters the stable stage. In the stable stage, the load value decreases slightly $(1-2 \mathrm{kN})$ compared with the peak value, and then remains stable in the process of about $40 \mathrm{~mm}$ displacement after the peak value.

During the cyclic loading process of T-anchorage system, there are two inflection points and three stages in the load-displacement curve. Similar to TC-anchorage system, the load-displacement curve is elastic before the first inflection point (yield point), which is basically linear. The curve between yield point and the second inflection point (peak point) is the plastic stage, which shows a non-linear and non-uniform increase relationship. In this stage, the bolt-slurry interface enters a stage of plastic deformation with a certain amount of elastic deformation. This phenomenon can be evidenced by the elastic and plastic strains in the load-displacement curves of the two cyclic loading processes. When the load reaches peak point, load-displacement curve enters the failure stage, which includes three processes. First, during the displacement of about $5 \mathrm{~mm}$ after the peak point, the load shows a sharp decline $(8-10 \mathrm{kN})$. Then, the load increases slightly $(2-3 \mathrm{kN})$ during the next $4 \mathrm{~mm}$; Thereafter, during the next $70 \mathrm{~mm}$ displacement, the load (residual load) remained basically stable.

Moreover, according to the characteristics of loaddisplacement curves of two kinds of anchorage systems, TC-anchorage system shows greater ultimate load and ductility than $\mathrm{T}$-anchorage system. This is manifested in: (1) although the load at the yield point of TC-anchorage system and $\mathrm{T}$ system are both $8 \mathrm{kN}$, the displacement at 


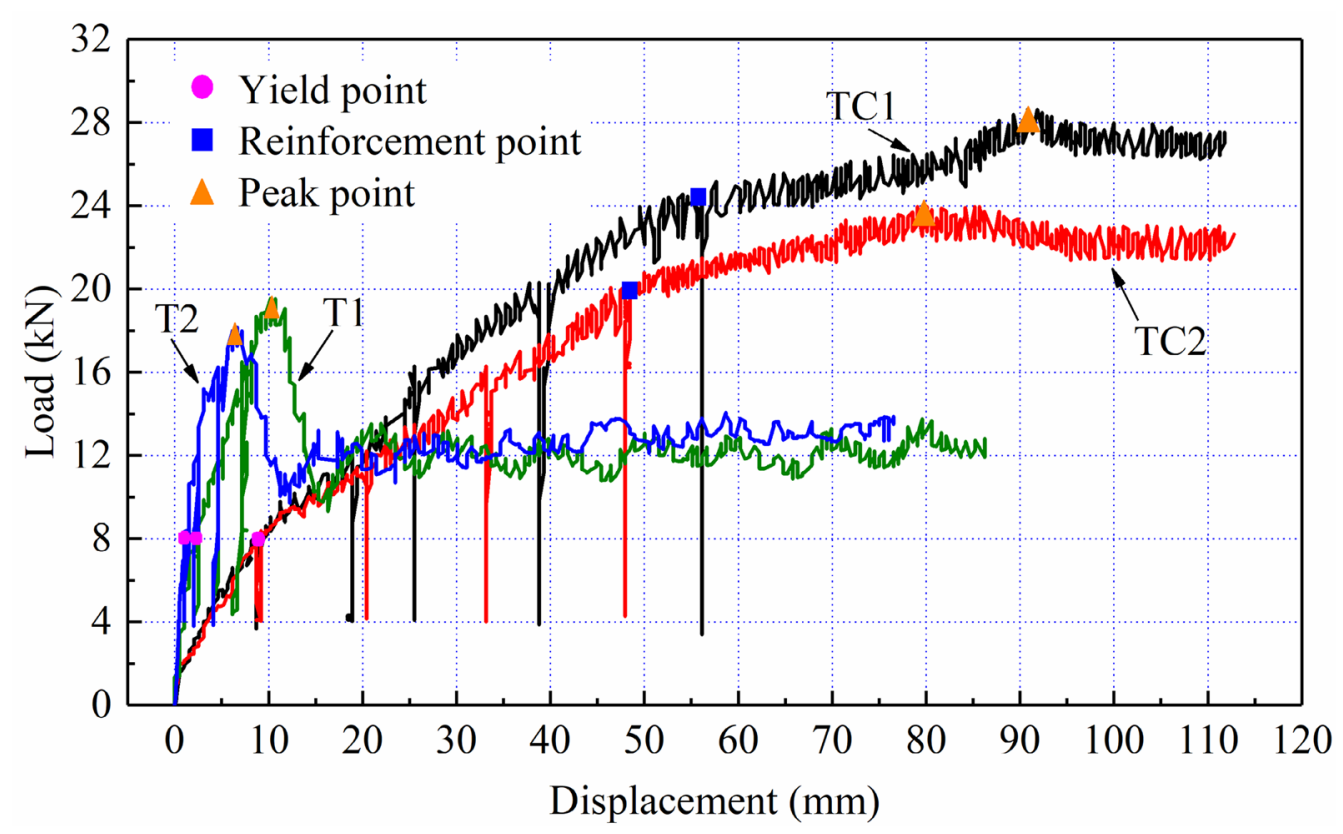

Fig. 7 Load-displacement curves of two types of anchorage systems

the yield point of TC-anchorage system is about $7.5 \mathrm{~mm}$ larger than that of T-anchorage system. (2) The loaddisplacement curve of TC-anchorage system has more reinforcement point and reinforcement service stage than that of T-anchorage system, and this reinforcement service stage has the characteristics of small increase of load and large increase of displacement. (3) The displacement of the peak point of TC-anchorage system is 7-14 times of that of T-anchorage system. (4) The post-peak load of T-anchorage system decreases sharply and the residual load is about $60-70 \%$ of the peak load. However, the residual load of TC-anchorage system anchorage system decreases only slightly, which is about $92-97 \%$ of the peak load and remains stable during the process of large displacement. Therefore, from the results and analysis of load-displacement curves of two kinds of anchorage systems, it can be concluded that T-anchorage system is a typical burst failure mode, while TC-anchorage system is an ideal progressive reinforced failure mode. The TCanchorage system exhibits the expected characteristics of "high anchorage force, large deformation resistance". The TC-anchorage system still provides considerable anchorage force when large deformation (e.g., over $80 \mathrm{~mm}$ ) occurs.

\section{Strain distribution along the embedment length}

Figure $8 \mathrm{a}, \mathrm{b}$ shows the distribution of interfacial strain along the embedment length of each anchorage system under different levels of load. For TC1-anchorage system: (1) Elastic stage $(0 \rightarrow 8 \mathrm{kN})$. In $0 \rightarrow 4 \mathrm{kN}$ stage, the curve shows a positive skewness curve (a short curve on the left side and a long curve on the right side) with a peak value at $\mathrm{L}=20 \mathrm{~cm}$, in other words, the strain increases sharply from $\mathrm{L}=0$ to $\mathrm{L}=20 \mathrm{~cm}$, and decreases from $\mathrm{L}=20$ to $\mathrm{L}=100 \mathrm{~cm}$. In $4 \rightarrow 8 \mathrm{kN}$ stage, the strain of each monitoring point increases with the increase of load in varying degrees and the curve is still positive skewness distribution, but the peak value appears at $\mathrm{L}=40 \mathrm{~cm}$. This phenomenon shows that in $0 \rightarrow 8 \mathrm{kN}$ stage, the pull-out effect mainly occurs in the front of the embedment length. With the increase of load, the peak strain shifts back, that is, the pull-out stress of the interface transfers to the end of the embedment length. (2) Plastic stage $(8 \rightarrow 24 \mathrm{kN})$. In $8 \rightarrow 12 \mathrm{kN}$ stage, the curve still shows a positive skewed single peak distribution. Although the peak value is still at $\mathrm{L}=40 \mathrm{~cm}$, the strain increment at $\mathrm{L}=40-100 \mathrm{~cm}$ is much larger than that at $\mathrm{L}=0-20 \mathrm{~cm}$. In $12 \rightarrow 16 \mathrm{kN}$ stage, the curve has a double peak shape, the higher peak value is $\mathrm{L}=40 \mathrm{~cm}$, the lower peak value is slightly prominent at $\mathrm{L}=80 \mathrm{~cm}$, and the strain increment at $\mathrm{L}=60-100 \mathrm{~cm}$ is much larger than that at $\mathrm{L}=0-40 \mathrm{~cm}$. During the period of $16 \rightarrow 20 \mathrm{kN}$, the double peak position of the curve remained unchanged, except that the strain at the peak value of $\mathrm{L}=80 \mathrm{~cm}$ increased significantly. In $20 \rightarrow 24 \mathrm{kN}$ stage, the strain increment at $\mathrm{L}=60-100 \mathrm{~cm}$ is much larger than that at $\mathrm{L}=0-40 \mathrm{~cm}$, and the peak value at $\mathrm{L}=80 \mathrm{~cm}$ has exceeded that at 


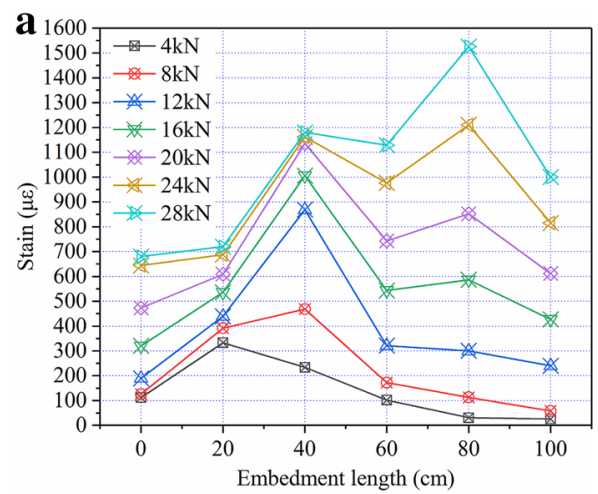

b
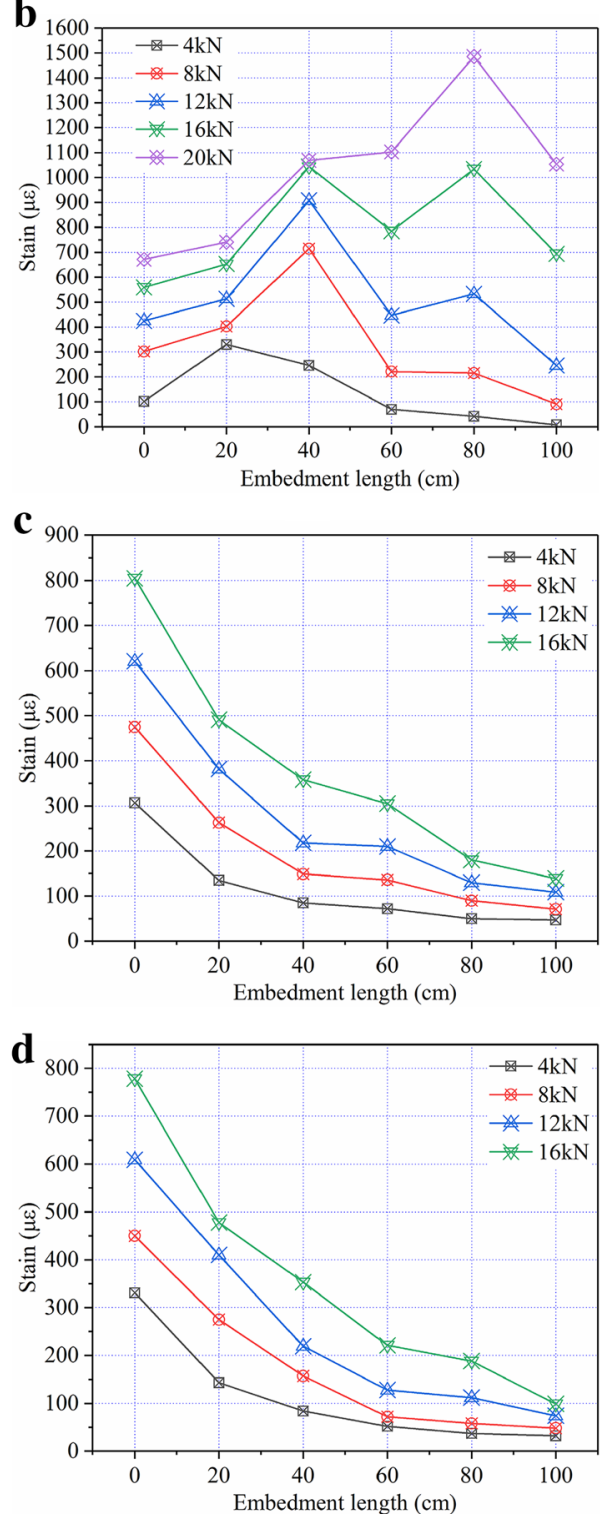

Fig. 8 Strain distribution curve of bolt-slurry interface along embedment length. a TC1, b TC2, cT1, dT2
$\mathrm{L}=40 \mathrm{~cm}$. During the $8 \rightarrow 24 \mathrm{kN}$ period, the curve experienced the typical stages of positive skewness, double peaks of front-high and back-low, and double peaks of front-low and back-high. The above phenomena show that: In this process, the interface strain at the back of the embedment length increases gradually, and the uplift resistance provided by the back of the embedment length increases gradually. The bolt-slurry interface at the front of the embedment length is gradually decoupled and the main pull-out action section is gradually transited from the front tension anchorage section to the back end of the tension anchorage section and the pressure-bearing body to bear together. (3) Reinforcement service stage $(24 \rightarrow 28 \mathrm{kN})$ : In this stage, the curve shows a single peak distribution with negative skewness, and the peak value is at $\mathrm{L}=80 \mathrm{~cm}$. The closer the measuring point is to $\mathrm{L}=80 \mathrm{~cm}$, the greater the strain increase is. This indicates that the main pull-out part has transited to $\mathrm{L}=80-100 \mathrm{~cm}$, in other words, the pressure-bearing body plays the main pullout role.

The distribution of interfacial strain along embedment length in TC2-anchorage system is similar to that in TC1-anchorage system: (1) Elastic stage $(0 \rightarrow 8 \mathrm{kN})$. The curve path has a positive skewed single peak distribution, and the peak value shifts from $\mathrm{L}=20$ to $\mathrm{L}=40 \mathrm{~cm}$. (2) Plastic stage $(8 \rightarrow 16 \mathrm{kN})$ : The curves show double peaks at $\mathrm{L}=40 \mathrm{~cm}$ and $\mathrm{L}=80 \mathrm{~cm}$ respectively, and the strain increment in $L=60-100 \mathrm{~cm}$ is much larger than that in $\mathrm{L}=0-40 \mathrm{~cm}$. The curve also shows a transition from the double peaks of front-high and back-low to the double peaks of front-low and back-high. (3) Reinforcement service stage $(16 \rightarrow 20 \mathrm{kN})$ : the curve shows a negative skewness single peak shape and the peak value is at $\mathrm{L}=80 \mathrm{~cm}$. The above phenomena show that: with the continuous increase of pull-out load, the strain in front of embedment length increases slightly, while the strain in back of embedment length increases substantially. The position where the bolt-slurry interface provides the main pullout resistance is transferred to the end of embedment length. The larger the load is, the stronger the pull-out resistance of the back part of the embedment length of TC-anchorage system can be.

As shown in Fig. 8c, d, the strain distribution curve of the bolt-slurry interface in T-anchorage system shows a negative exponential decay along the embedment length, and the peak strain is always at $\mathrm{L}=0 \mathrm{~cm}$. With the increase of load, the strain of each measuring point increases. The closer the measuring point is to $\mathrm{L}=0 \mathrm{~cm}$, the greater the strain increase is, and the more significant the curve attenuation is. The strain mainly distributes in $\mathrm{L}=0-40 \mathrm{~cm}$. This phenomenon is similar to the results of previous studies $[17,18]$, that is, the strain distribution 
at the bolt-slurry interface is not uniform, and the stress mainly concentrates on the front end of the embedment length.

The strain distribution along embedment length of T-anchorage system decreases negatively exponentially from low load to high load, and the strain increment is always large in the range of $\mathrm{L}=0-40 \mathrm{~cm}$, which fully shows that only the front end of embedment length plays a major role in uplift resistance. However, the strain distribution along embedment length of bolt-slurry interface in TC-anchorage system is unimodal positive skewness distribution under low load; It is in the process of bimodal dynamic transition from high front peak-low back peak to low front peak-high back peak under the load from low to high; It presents a unimodal negative skewness distribution under ultimate load. Distribution of strain at bolt-slurry interface along embedment length of TC-anchorage system shows that the whole embedment length plays a full role in pull-out, especially in the pressure-bearing section. Obviously, TC-anchorage system has more reasonable spatio-temporal continuity than T-anchorage system. However, it is noteworthy that TCanchorage system still has defects. Under different levels of loads, the whole bolt-slurry interface of TC-anchorage system is not an ideal uniform force, but a local force mode which transfers from the front end of embedment length to the back end of embedment length in stages. Although this force mode can ensure the continuity of the force on the interface, it is not conducive to greatly improving the ultimate load of TC-anchorage system.

\section{Failure law}

During the pull-out test, there were no cracks in the heritage sites soil, and the bolts were not broken. All tests were forced to stop when the displacement of anchor head cannot converge or the pull-out load cannot increase. Observing the external phenomena of field parallel test (Fig. 9a), the bolts of the two anchorage systems were pulled out in slurry and a few radial cracks appeared in slurry near the orifice (the front end of embedment length). After pulling out the bolts of the two kinds of anchorage systems, the failure modes of the two kinds of anchorage systems show obvious differences: (1) there is a certain amount of slurry bonding on the whole bolt surface of T-anchorage system. The slurry-soil interface did not exhibit debonding and slippage. There is no excessive damage to the slurry in the hole, and slurry powder residues at the bottom of the hole (Fig. 9b). The local slurry in the hole presents threads mosaic with the shape of the bolt, and there are rough scratches in the local slurry. (2) There is a certain amount of slurry bond on the surface of TC-anchorage system bolt with the whole embedment length. The slurry forms a conical slurry based on the pressure-bearing body at the end of the bolt (Fig. 9c). The surface of the conical slurry has friction marks and is smooth. The slurry in the anchor hole is broken, and the hole wall is partly scratched and relatively complete. Observing the residual slurry in the anchor hole, it has become small fragments or powders. There is a thin-bedded slurry bonding somewhere in the inner wall of the hole, and some of the thin layer of soil on the surface of the hole wall appears fresh friction fracture marks.

The measured heights of conical slurry of TC1-anchorage system and TC2-anchorage system are $55 \mathrm{~mm}$ and $50 \mathrm{~mm}$ respectively, and the calculated angles between the conical surface and the bottom are $66.43^{\circ}$ and $64.36^{\circ}$ degree, respectively (Fig. 9d). According to MohrCoulomb criterion, the internal friction angle of conical slurry can be obtained by Eq. (4). The formula is as follows:

$$
\alpha=45^{\circ}+\varphi / 2
$$

where $\alpha$ is the angle between the direction of conical surface and the direction of the hollow truncated cone plane; $\phi$ is the internal friction angle of the conical slurry. The units of $\alpha$ and $\phi$ are the degree $\left(^{\circ}\right)$.

The calculated values of TC1-anchorage system and TC2-anchorage system are $42.86^{\circ}$ and $38.73^{\circ}$ respectively, which are not much different from the internal friction angle $\left(\phi=41.92^{\circ}\right)$ measured in laboratory. This shows that the conical surface is a shear fracture surface formed by the combined action of the maximum principal stress provided by the hollow truncated cone and the small principal stress provided by the hole wall of heritage site soil.

From the analysis of the above phenomena and results, it can be concluded that slurry shearing and dilational slip lead to the debonding and decoupling of the bolt-slurry interface in T-anchorage system. The failure mode of tension section of TC-anchorage system is consistent with that of $\mathrm{T}$-anchorage system, but the failure mode of pressure-bearing section is completely different. The difference between the failure modes of the two anchorage systems is mainly related to the stress mode of the confined structure in the pressure-bearing section of $\mathrm{TC}$-anchorage system. The failure mode of pressure-bearing section of TC-anchorage system is that slurry is cut into the conical slurry. According to Mohr strength theory, the shear strength of failure surface is related to the properties of slurry and the normal stress of failure surface. Under the confining pressure produced by pressure-bearing body, anchor hole wall and slurry in the tension section, normal stress of slurry failure surface in the pressure-bearing section is effectively increased, which effectively improves shear strength of slurry. After the formation 


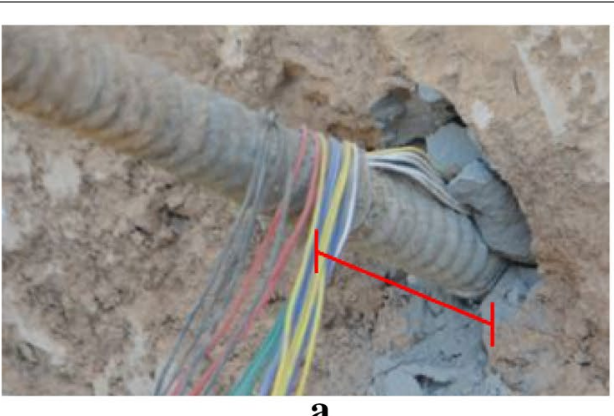

a

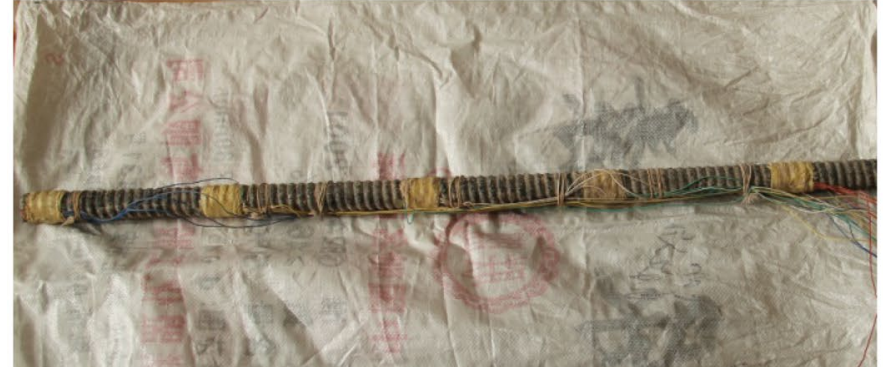

b
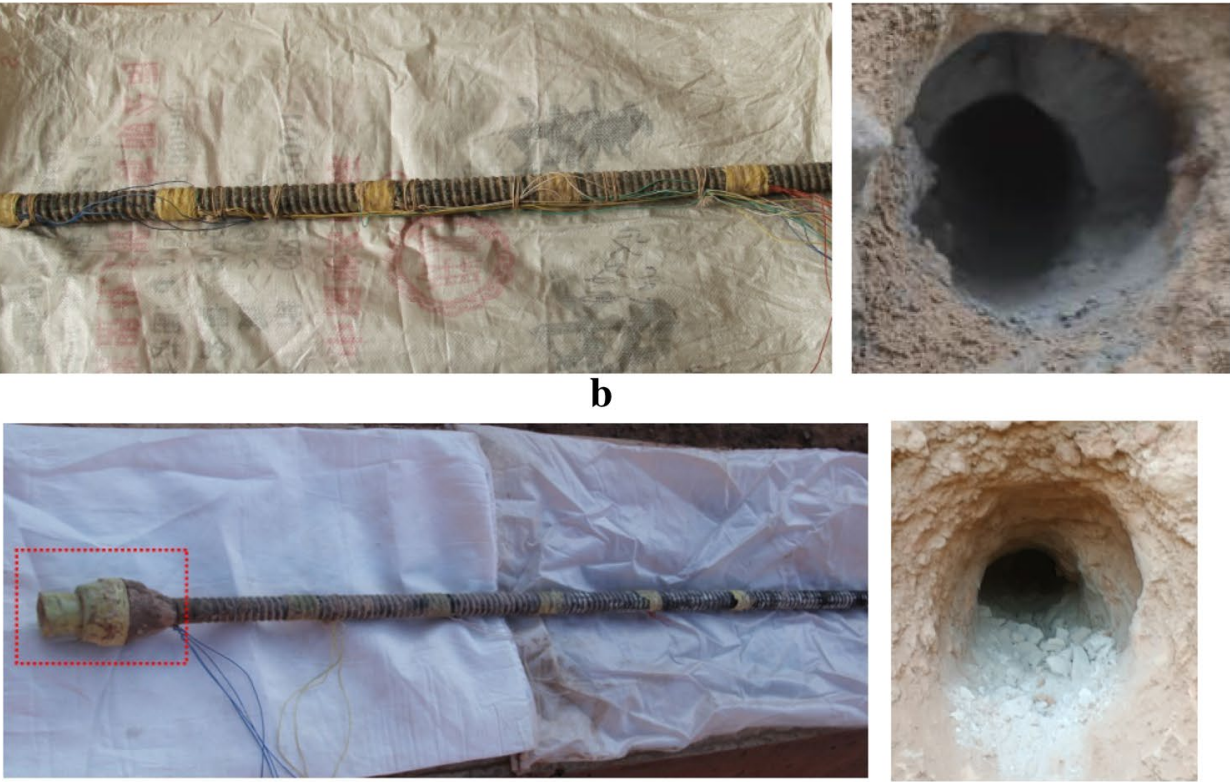

c

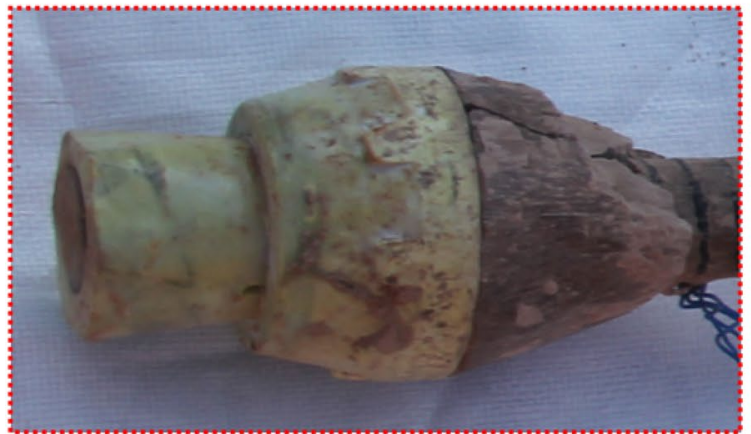

d

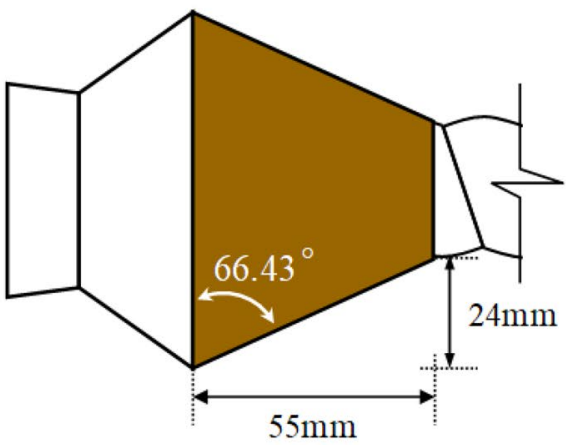

Fig. 9 Failure law of two types of anchorage system. a Phenomenon at the Orifice of failure anchorage system, $\mathbf{b}$ pulled T-bolt and failure hole, $\mathbf{c}$ pulled TC-bolt and failure hole, $\mathbf{d}$ the angle between the bottom of the conical slurry and the failure surface of TC1-anchorage system

of conical slurry, under the continuous pull-out load, conical slurry moves forward to compact its peripheral slurry. The confining pressure of the hole wall and the compressive performance of slurry in the compaction zone will be fully utilized, which once again forms an effective pull-out effect on the conical slurry of TCanchorage system. It is also revealed that the pull-out performance of $\mathrm{TC}$-anchorage system depends on the shear and compressive properties of slurry in the pressure-bearing section. 


\section{Discussion}

Based on the results and analysis of failure mode, ultimate load, load-displacement relationship and interface strain distribution along embedment length of in situ pull-out test of TC-anchorage system, it can be concluded that the TC-anchorage system has excellent anchorage performance. In order to have a clearer understanding of the working mechanism of TC-anchorage system, it is necessary to make a preliminary discussion on the experimental results, the failure mechanism of the anchorage system and the mechanism of the mechanical interaction between the bolt and the slurry.

According to the existing research [32] and the experimental results, it is pointed out that the working mechanism of TC-anchorage system includes three progressive stages. First, the debonding-decoupling of bolt-slurry interface: This stage is similar to the mechanical behavior of the debonding-decoupling of the bolt-slurry interface in the $\mathrm{T}$-anchorage system. There are weak chemical bonding force, strong friction and mechanical occlusion force between the bolt and slurry in the tensile anchorage section. This stage mainly occurs in the elastic stage. The main pull-out force is determined by the frictional resistance of the tensile anchorage section, and the pressurebearing body is subjected to smaller static earth pressure (Fig. 10a). From the point of view of the bond force of the bolt-slurry interface in the whole tension section, the bond weakens at the front end of the anchorage and keeps moving backward, which can be demonstrated by the phenomenon that the strain increment at the front end of the embedment length is small, the increment at the back end is large and the location of peak strain moves backward.

Secondly, the formation of conical slurry: After the peak value of static friction is reached in the tension section, if the load continues to increase, the pressurebearing body will begin to move forward obviously and its pressure on the slurry will increase. The slurry in front of the pressure-bearing body begins to produce a conical local shear surface under the restraint of the hole wall and the constant compression of the bearing plate (Fig. 10b). If the external tension of bolt continues to increase, the conical shear surface of slurry expands from bottom to top, and gradually connects to form a conical surface. Finally, the sheared slurry and the pressure-bearing body form a expansion (Fig. 10c). This stage mainly occurs in the plastic stage and a large displacement occurs between the bolt and the slurry. At this stage, the mechanical deformation performance of the bolt is determined by the friction of the tension section and the shear and compressive strength of the slurry. These phenomena can be confirmed by the characteristics of the progressive change process of strain distribution curve along embedment length in plastic stage, in which the curve changes from positive skewness single peak curve to high front peak-low back peak double peak curve, and then to low front peak-high back peak double peak curve.

Finally, compaction and crushing of slurry: After the formation of the conical slurry, the compression and crushing deformation of the slurry is larger than the shear deformation, that is, the load-displacement curve has an obvious inflection point (reinforcement point), and then immediately entered reinforcement service stage. As the load continues to increase, the conical slurry will move forward greatly. The slurry around the conical slurry is constrained by the confining pressure of the hole wall, and is sheared, broken and continuously compacted under the compression of the conical slurry. The slurry pressed into powder is extruded from the gap between the conical slurry and the hole wall and filled in the cavity area behind the pressure-bearing body (Fig. 10d). This is consistent with the phenomenon of residual slurry powder at the bottom of anchor hole after the TC-bolt was pulled out. When the pull-out effect caused by the cone reaches its limit state, the load also reaches its peak value. The process of compression of slurry by the conical slurry continues, and the conical effect achieves a dynamic and stable equilibrium, which is manifested in that the load does not decrease in the process of a certain displacement (at least about $40 \mathrm{~mm}$ ) occurring in the residual stage after the peak. At this stage, the mechanical deformation performance of the bolt is determined by the compaction and crushing deformation performance of slurry in front of the conical slurry. The tension section provides less friction, and the pull-out resistance is mainly provided by the rear conical slurry. This can be proved by the negative skewness single peak (peak $\mathrm{L}=80 \mathrm{~cm}$ ) curve of strain distribution with embedment length in the reinforcement service stage.

Comparing the above analysis results of the working mechanism of TC-anchoring system with the expected results from theoretical prediction, it can be seen that there are differences between the two. The test results indicate that the working mechanism of the bolt-slurry interface of TC-anchorage system in the initial debonding-decoupling stage is the same as that of the " $\mathrm{T}$ " model (Fig. 3) predicted by theory. In the following stress process, TC-anchorage system does not crush slurry in the pressure-bearing section completely as the " $\mathrm{T}$ " model predicted by theory, but actually shears slurry in the pressure-bearing section into a conical slurry. After the formation of conical slurry, the conical slurry and pressure-bearing body have been integrated into a whole. Its mechanical structure is similar to the "Y" type (Fig. 10c), and is no longer the " $\mathrm{T}$ " model predicted by theory. TC-anchorage system compacts the periphery slurry 


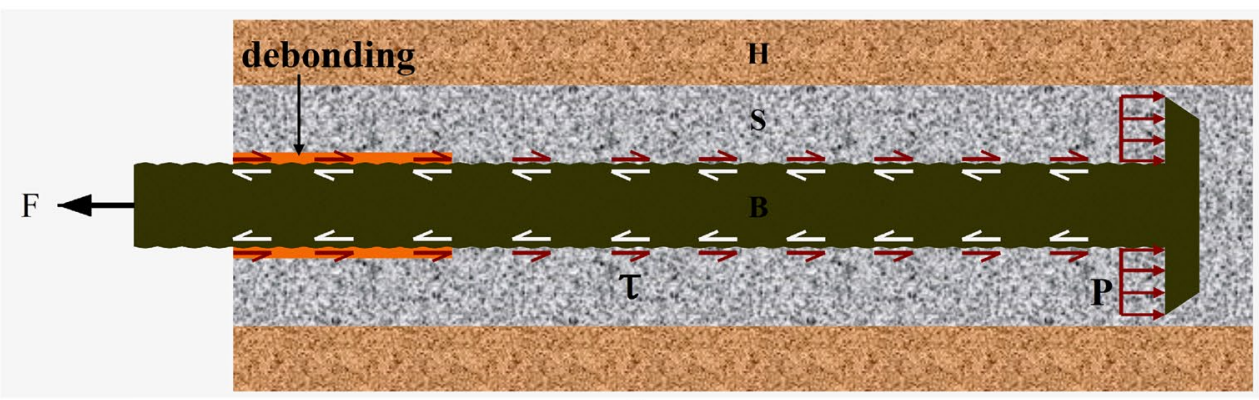

$\mathbf{a}$

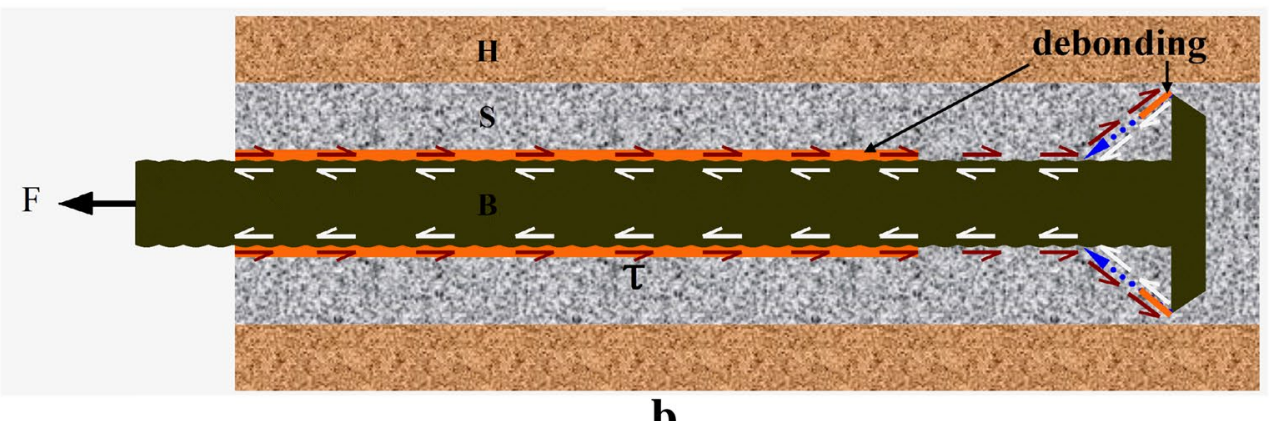

b

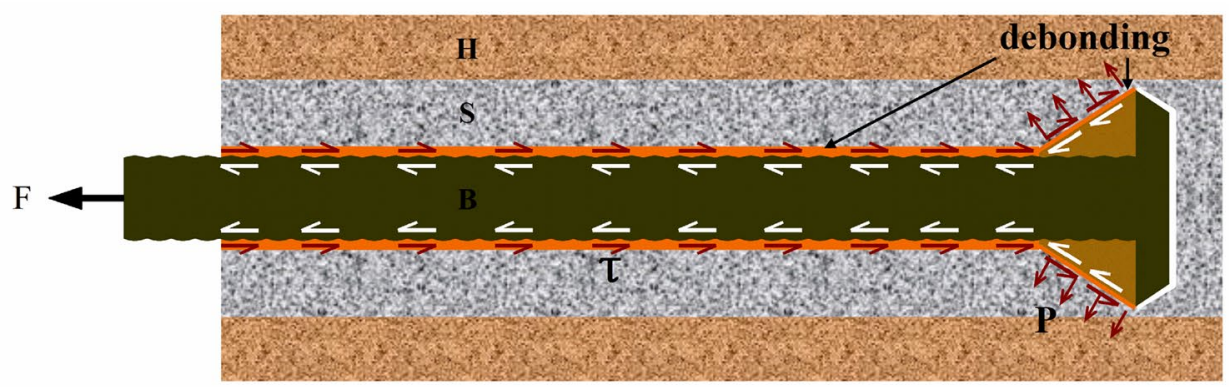

c

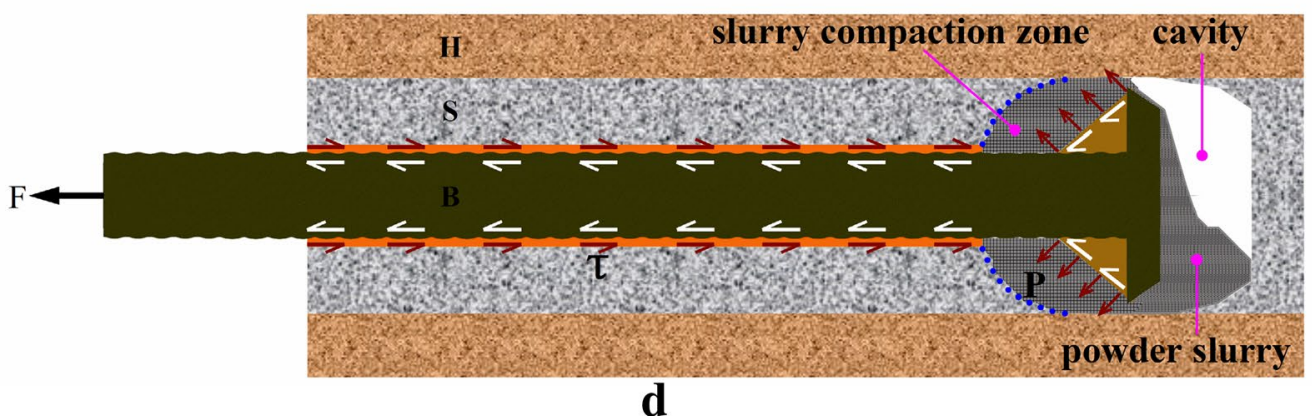

Fig. 10 Working mechanism of TC-anchorage system. a Tension section subjected to friction and pressure-bearing body subjected to static earth pressure, $\mathbf{b}$ conical surface penetrates gradually, $\mathbf{c}$ conical slurry formation, $\mathbf{d}$ compaction and crushing of slurry. F: drawing force; $\tau$ : shear stress; $P$ : pressure; B: bolt; S: slurry; H: heritage sites soil

of conical slurry with "Y" type stress structure in slurry compaction zone. Although the actual "Y" structure is different from the theoretical " $\mathrm{T}$ " model (vertical compression slurry), the " $Y$ " structure effectively increases the shear surface area of slurry and still makes good use of the confining pressure of pore wall and the compressive performance of slurry. All in all, the anchorage force of the new TC-anchorage system is $40 \%$ higher than that of $\mathrm{T}$-anchorage system, which really realizes "short anchorage, high anchorage force". In engineering 
practice, TC-bolt can effectively reduce the embedment length and number of bolts compared with T-bolt under the same anchorage force requirement, thus effectively reducing the protective damage caused by anchorage engineering to earthen heritage sites. The peak point displacement of TC-anchorage system is about 7-14 times of that of T-anchorage system, that is to say, TC-anchorage system can provide considerable anchorage force even if there is a large deformation $(80-91 \mathrm{~mm})$. Moreover, it should be also noted that the residual load after the peak point of TC-anchorage system still reaches $92-97 \%$ of the peak load, and remains stable during the process of accompanying bolt displacement of more than $40 \mathrm{~mm}$, which fully increases the storage of safe deformation of anchorage structure. In the process of small increase of pull-out load, the strain distribution at bolt-slurry interface of TC-anchorage system has the phenomenon of alternating transfer from positive skewness to bimodality and then to negative skewness, which reveals that the interfacial force gradually transfers from the front end to the back end of embedment length and gradually reaches a stable state after the back end of embedment length is stressed. TC-anchorage system is superior to T-anchorage system whose interface stress is concentrated at the front end of embedment length. In other words, TCanchorage system shows more reasonable spatio-temporal continuity than $\mathrm{T}$-anchorage system in the force mode of bolt-slurry interface.

In summary, $\mathrm{TC}$-anchorage system exhibits more reasonable working mechanism than T-anchorage system, which achieves its high anchorage force and strong ductility characteristics. This feature has been confirmed in the present conservation situation of earthen heritage sites. The scale and stability of earthen heritage sites with reinforced structures are obviously more excellent than those without reinforced structures. For example, in the Great Wall and beacon towers of the Han and Ming Dynasties [33], the Juyan sites, the Kizil Gaha beacon tower, the Loulan sites, and the ancient city of Songshan (Fig. 11), although some of the earthen heritage sites have been deformed and cracked, they have not collapsed due to the existence of irregular reinforcement structure. The excellent anti-large deformation reinforcement model of TC-anchorage system can adjust the self-stability of

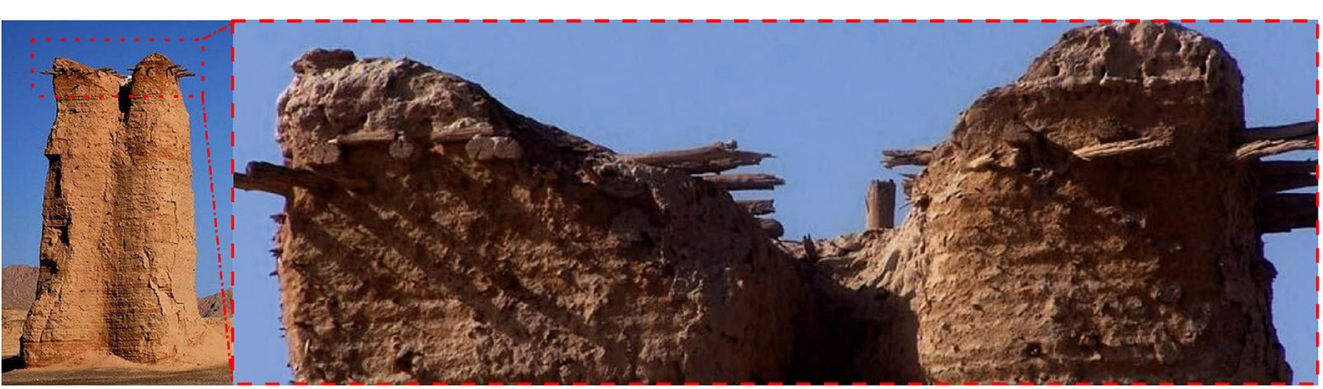

$\mathbf{a}$

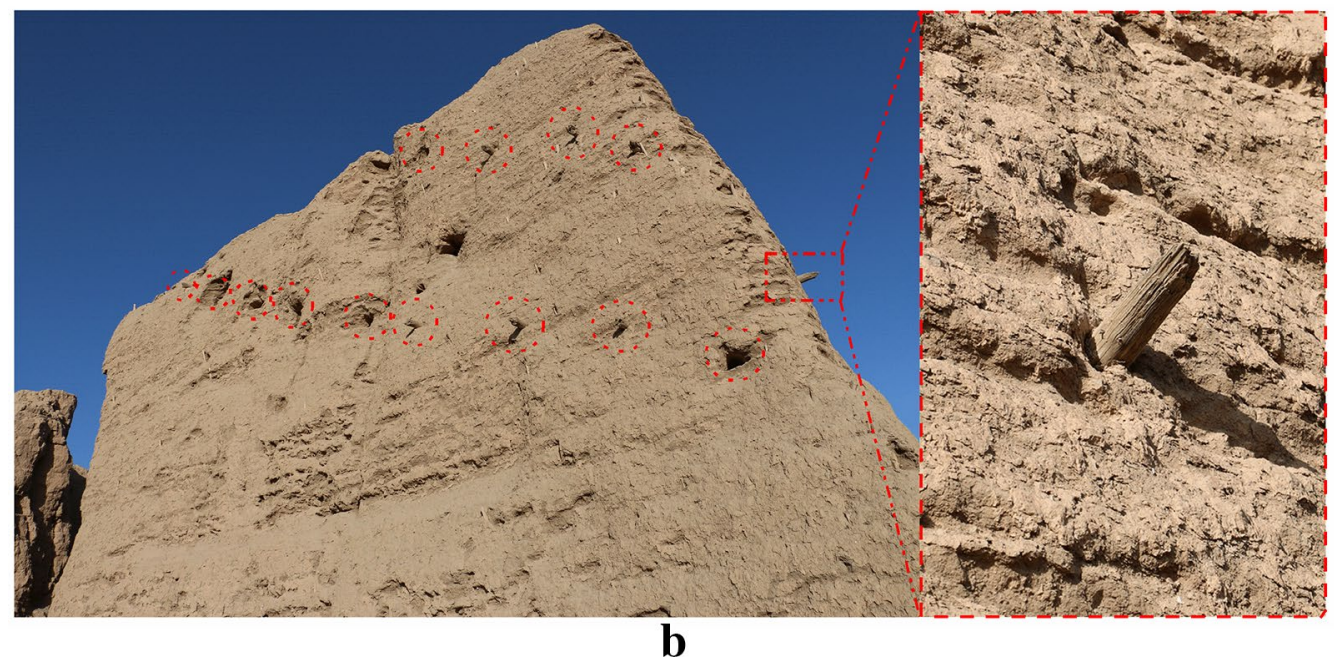

Fig. 11 Application of irregular reinforced structures in the control of mechanical stability of earthen heritage sites. a Kizil Gaha beacon tower reinforced by wood in Tang Dynasty (Kuqa, Xinjiang, China), b wooden poles embedded in the walls of Songshan ancient city in Ming Dynasty (Tianzhu, Gansu, China) 
heritage sites soil to a great extent and is beneficial to the seismic performance of the self-structure of heritage sites soil, which ensures that the latter reinforcement measures (reinforcement of earthen heritage sites by bolts) play a similar role to the original construction (Wooden tendons are embedded in earthen heritage sites), thus forming a compatibility of physical, structural and mechanical significance.

\section{Conclusion}

(1) The average ultimate pull-out load of TC-anchorage system bolt is about $40 \%$ higher than that of $\mathrm{T}$-anchorage system, and its displacement at peak point is about 7-14 times of that of T-anchorage system, and the residual load after peak load is about $92-97 \%$ of that of peak load. TC-anchorage system has the characteristics of strong ductility with small elastic deformation and large plastic deformation.

(2) When the load is low, the strain distribution along the embedment length of the bolt-slurry interface in TC-anchorage system is positive skewness and single peak; when the load changes from low to high, it is in the process of double peak dynamic transition from high front peak-low back peak to low front peak-high back peak; when the ultimate load is applied, it presents a negative skewed single peak shape.

(3) The working mechanism of TC-anchorage system includes three stages: debonding of bolt-slurry interface, formation of conical slurry, and compaction and crushing of slurry, which belongs to typical progressive failure.

(4) The mechanism of mechanical interaction between bolt and slurry in TC-anchorage system fully realizes the synergistic utilization of compression and shear properties of slurry. Compared with $\mathrm{T}$-anchorage system, TC-anchorage system exhibits more reasonable time-space continuity and more excellent anchorage performance.

(5) According to the progressive working machine of TC-anchorage system, which includes the debonding-decoupling of bolt-slurry interface, the formation of conical slurry and compaction and crushing of slurry, the differential expressions and analytical solutions of shear stress around bolt, displacement and axial force of TC-bolt should be further constructed in the future to accurately explore the pullout load transfer characteristics of TC-anchorage system in earthen heritage sites.

\section{Abbreviations}

TC-anchorage system: fully grouted tension-compression composite anchorage system; T-anchorage system: fully grouted tension anchorage system; TCbolt: fully grouted tension-compression composite bolt; T-bolt: fully grouted tension bolt; GFRP: glass-fibre-reinforced plastic; SH: modified polyvinyl alcohol; CaO: quicklime; C: ground site soil; F: fly ash.

\section{Acknowledgements}

The research described in this paper was financially supported by the Natural Science Foundation of China (Grant No. 41562015 and No. 51208245) and the Program for Changjiang Scholars and Innovative Research Team in University of Ministry of Education of China (2017IRT17-51).

\section{Authors' contributions}

DW and KC were involved with the experimental designs and testing. GW was responsible for the sample collections and indoor experiments. DW, FF and $\mathrm{XY}$ performed the field experiments. This manuscript was written by KC and DW. KC also contributed to data analysis and processing. All authors read and approved the final manuscript.

\section{Funding}

The research described in this paper was financially supported by the Natural Science Foundation of China (Grant Nos. 41562015 and 51208245) and the Program for Changjiang Scholars and Innovative Research Team in University of Ministry of Education of China (2017IRT17-51).

\section{Availability of data and materials}

Most of the data on which the conclusions of the manuscript rely are published in this paper, and the full data are available for consultation upon request.

\section{Competing interests}

The authors declare that they have no competing interests.

\section{Author details}

${ }^{1}$ Western Center for Disaster Mitigation in Civil Engineering of Ministry of Education of China, School of Civil Engineering, Lanzhou University of Technology, Langongping Road No. 287, Lanzhou 730050, People's Republic of China.

2 Key Laboratory of Mechanics on Disaster and Environment in Western China, School of Civil Engineering and Mechanics, Lanzhou University, Tianshui South Road No. 222, Lanzhou, People's Republic of China.

Received: 17 March 2019 Accepted: 7 July 2019

Published online: 18 July 2019

\section{References}

1. Li ZX. Conservation of ancient sites along the silk road. Beijing: Science Press; 2010.

2. Du Y, Chen W, Cui K, Gong S, Pu T, Fu X. A model characterizing deterioration at earthen sites of the Ming Great Wall in Qinghai Province, China. Soil Mech Found Eng. 2017:53(6):426-34.

3. PuT, Chen W, Du Y, Li W, Su N. Snowfall-related deterioration behavior of the Ming Great Wall in the eastern Qinghai-Tibet Plateau. Nat Hazards. 2016;84:1539-50.

4. Benmokrane B, Zhang B, Chennouf A. Tensile properties and pullout behaviour of AFRP and CFRP rods for grouted anchor applications. Constr Build Mater. 2000;14(3):157-70.

5. Martin LB, Tijani M, Hadj-Hassen F, Noiret A. Assessment of the bolt-grout interface behavior of fully grouted rock bolts from laboratory experiments under axial loads. Int J Rock Mech Min Sci. 2013;63(10):50-61.

6. Ma SQ, Nemcik J, Aziz Z. An analytical model of fully grouted rock bolts subjected to tensile load. Constr Build Mater. 2013;49(12):519-26.

7. Wang XD. Philosophy and practice of conservation of soil architecture sites: a case study of the Jiaohe ancient site in Xinjiang. Dunhuang Res. 2010;6:5-9 (in Chinese).

8. Hyett AJ, Moosavi M, Bawden WF. Load distribution along fully grouted bolts with emphasis on cable bolt reinforcement. Int J Numer Anal Meth Geomech. 1996;20(7):517-44. 
9. Kilic A, Yasar E, Celik AG. Effect of grout properties on the pull-out load capacity of fully grouted rock bolt. Tunn Undergr Space Technol. 2002;17(4):355-62.

10. Cao C, Ren T, Cook C. Calculation of the effect of Poisson's ratio in laboratory push and pull testing of resin-encapsulated bolts. Int J Rock Mech Min Sci. 2013;64:175-80.

11. Zhang JK, Chen WW, Li ZX, Wang XD, He FG. Field tests on anchorage mechanism of wood bolts for conservation of soil sites. Chin J Geotech Eng. 2013;35(6):1166-71 (in Chinese).

12. Sun ML, Wang XD, Li ZX, Zhang JK. Study of the cohesional strength of reinforcing soil sites with a bamboo anchorage. Dunhuang Res. 2011;6:81-4 (in Chinese)

13. Zhang HY, Wang XD, Wang XD, Lü QF, Zhang YJ. Bond-slip model for bamboo-steel cable composite anchor. Rock Soil Mech. 2011;32(3):78996 (in Chinese).

14. Mao XF, Zhao D, Chen P. Anchor theory and experimental study of geofilament blot. Mech Pract. 2008;30(2):74-7 (in Chinese).

15. Zhang JK, Chen WW, He FG, Li ZX, Sun ML. Field experimental study on anchorage performance of GFRP at conservation earthen sites. J Eng Geol. 2014:22(5):804-10 (in Chinese).

16. Zhang JK, Li ZX, Chen WW, Wang XD, Guo QL, Wang N. Pull-out behaviour of wood bolt fully grouted by PS-F slurry in rammed earth heritages. Geomech Geoeng. 2017;12(4):279-90.

17. Cui K, Wang DH, Chen WW, Ren XF, Liu J, Yang G. Comparative study of anchorage performance of three types of bolts fully grouted by modified glutinous rice mortar. Rock Soil Mech. 2018;39(2):498-506 (in Chinese)

18. Cui K, Wang DH, Chen WW, Ren XF, Guan XP, Huang JJ. Performance and mechanism of bolts fully grouted with $\mathrm{SH}(\mathrm{C}+\mathrm{F})$ slurry. J Eng Geol. 2017;25(1):19-26 (in Chinese).

19. Zhang JK, Chen WW, Li ZX, Wang XD, Guo QL, Wang N. Study on workability anddurability of calcined ginger nuts-based grouts used in anchoring conservation of earthen sites. J Cult Herit. 2015;16(6):831-7.

20. Yang ST, Wu ZM, Hu XZ, Zheng JJ. Theoretical analysis on pullout of anchorage from anchor-mortar-concrete anchorage system. Eng Fract Mech. 2008:75(5):961-85.

21. WW/T 0038-2012. Design specification for preservation and reinforcement engineering of arid soil sites. Beijing: State Administration of Cultural Heritage; 2012.
22. CECS 22:2005. Technical specification for ground anchors. Beijing: China Association for Engineering Construction Standardization; 2005.

23. JGJ63-2006. Standard of water for concrete. Beijing: Ministry of housing and urban-rural development of the People's Republic of China; 2006

24. Chen WW, Guo ZQ, Xu YR, Chen PP, Zhang S, Ye F. Laboratory tests on rammed earth samples of earthen sites instilled by reinforcement material SH. Chin J Geotech Eng. 2015;37(8):1517-23 (in Chinese).

25. GB/T50123-1999. Standard for soil test method. Beijing: General Administration of quality supervision, inspection and Quarantine of the people's Republic of China, and Ministry of housing and urban-rural development of the People's Republic of China; 1999.

26. WW/T 0039-2012. Testing techniques specifications for preservation of soil sites. Beijing: State Administration of Cultural Heritage; 2012.

27. GB 50086-2015. Technical code for engineering of ground anchorages and shotcrete support. Beijing: China Metallurgical Construction Association; 2015.

28. Kilıc A, Yasar E, Atis CD. Effect of bar shape on the pull-out capacity of fully-grouted rockbolts. Tunn Undergr Space Technol. 2003;18(1):1-6.

29. Kim G, Ahn K, Min K, Jung C. Behavior characteristics of underreamed ground anchor through field test and numerical analysis. J Korean Math Soc. 2013;14(8):37-44 (In Korean).

30. Tu BX, Yu J, He JF, Cheng Q, Xu GP, Jia JQ. Analysis of anchorage performance on new tension-compression anchor II: model test. Chin J Geotech Eng. 2019;41(3):475-83 (in Chinese).

31. Li ZX, Sun ML, Wang XD. Conservation research on Jiaohe ruins. Beijing: Science Press; 2008.

32. Zhang N, Wu HN, Shen JSL, Hino T, Yin ZY. Evaluation of the uplift behavior of plate anchor in structured marine clay. Mar Georesour Geotechnol. 2017;35(6):758-68.

33. Chen W, Du Y, Cui K, Fu X, Gong S. Architectural forms and distribution characteristics of beacon towers of the Ming Great Wall in Qinghai Province. J Asian Archit Build Eng. 2017;16(3):503-10.

\section{Publisher's Note}

Springer Nature remains neutral with regard to jurisdictional claims in published maps and institutional affiliations.

\section{Submit your manuscript to a SpringerOpen ${ }^{\circ}$ journal and benefit from:}

- Convenient online submission

- Rigorous peer review

- Open access: articles freely available online

- High visibility within the field

- Retaining the copyright to your article

Submit your next manuscript at $\boldsymbol{\nabla}$ springeropen.com 